\title{
COMUNICACIÓN
}

\section{Presencia de anticuerpos contra Trypanosoma cruzi en perros de Costa Rica}

\author{
LILIANA REYES, ERICKA SILESKY, CARLOS CERDAS, MISAEL CHINCHILLA y OLGA GUERRERO
}

\section{PRESENCE OF ANTIBODIES AGAINST Trypanosoma cruzi IN COSTA RICAN DOGS}

Trypanosoma cruzi antibody presence was studied in pet and stray dogs from endemic and non endemic zones. Five percent of pet dogs from endemic zones were positive against a $1.6 \%$ from non endemic areas. Twelve percent of stray dogs were positive independent of the procedence.

Key words: Trypanosoma cruzi, Chagas disease, Canine trypanosomosis, Costa Rica.

\section{INTRODUCCIÓN}

La Enfermedad de Chagas es una parasitosis típica del Continente Americano y se distribuye desde Estados Unidos hasta Sur América ${ }^{1}$. El agente etiológico, Trypanosoma cruzi, es trasmitido por insectos reduvideos y se mantiene en la naturaleza parasitando gran cantidad de reservorios tales como marsupiales, perros, roedores domésticos y gatos. El estudio de éstos es importante para determinar la presencia de tripanosomátidos y el riesgo inmediato para las personas de contraer la enfermedad dado el contacto cercano con ellos ${ }^{2}$.

Los perros y los gatos pueden actuar como reservorios intradomiciliares y/o peridomiciliares tal como ha sido en Argentina demostrado en donde se ha informado un $41 \%$ de perros infectados y $39 \%$ gatos infectados por T. cruzi $^{3}$. En Costa Rica se demostró una positividad de
9,9\% en perros de una zona endémica ${ }^{4}$.

La presente investigación estudia la prevalencia de anticuerpos en perros mascota y callejeros provenientes de varias zonas endémicas y no endémicas de nuestro país.

\section{MATERIAL Y MÉTODOS}

Se colectaron sueros de 61 perros mascota y 55 de perros callejeros de zonas endémicas. De las zonas no endémicas se analizaron 62 perros mascota y 8 perros callejeros. Las muestras fueron conservadas a $-20^{\circ} \mathrm{C}$ hasta su análisis. Se utilizaron dos técnicas de ELISA comercial, adaptadas para la determinación de anticuerpos en perros $^{5}$. Brevemente, el EIAgen $T$. cruzi (Biochem ImmunoSystems Italia S.P.A. Bologna Italia) y el Chagatest ELISA recombinant v.3.0 (Wiener Laboratorios S.A.I.C., 2000 Rosario Argentina), fueron adaptadas utilizando

Centro de Investigación en Enfermedades Tropicales (CIET)

Facultad de Microbiología, Universidad de Costa Rica.

Correspondencia: Dra. Liliana Reyes Lizano, Facultad de Microbiología, Centro de Investigación en Enfermedades Tropicales, Universidad de Costa Rica. 
un anti IgM de perro marcado con peroxidasa (Sigma A9042, St. Louis, M.O. 63103, USA) como conjugado. Se consideraron positivos únicamente los sueros que lo fueron en las dos determinaciones.

\section{RESULTADOS}

La Tabla 1 muestra el porcentaje de positividad por $T$. cruzi en perros en estudio. En los perros mascota de zonas endémicas se encontró un $5,2 \%$ de positividad mientras que en las zonas no endémicas fue de $1,6 \%$. En cuanto a perros callejeros, el porcentaje de positividad fue de $12 \%$, independiente de si fueron capturados en zonas endémicas o no-endémicas. Del total de las muestras analizadas el 6,2\% de las muestras fueron positivas.

Con referencia al sexo, el 5\% de las hembras y el $10 \%$ de los machos fueron positivas.

\section{DISCUSIÓN}

La tripanosomosis americana es una zoonosis en la que participan tanto reservorios selváticos como peridomiciliares e intradomiciliares ${ }^{2}$. Estudios realizados en la Argentina han demostrado la importancia del perro como reservorio intradomiciliar en la transmisión del parásito por Triatoma infestans ${ }^{6,7}$. Se considera que excluir de las habitaciones los animales domésticos, principalmente perros, puede reducir de manera importante la transmisión a los humanos ${ }^{8}$.

En Costa Rica, en San Rafael de Ojo de Agua, localidad endémica por tripanosomiasis entre los años 1964 y 1968 se encontró un $34,4 \%$ de ratas positivas por el parásito y en el zorro pelón, principal reservorio peridomiciliar, una positividad de $6,5 \%$ por métodos directos (xenodiagnóstico) ${ }^{4,9}$. En cuanto a los reservorios intradomiciliares se informa de una positividad en gatos de $2,9 \%$ y en perros de $9,8 \%$. Sin embargo, cuando se hace la relación de perros con la presencia de triatominos, el porcentaje de perros positivos aumenta al 14,5\% ${ }^{4}$.

En el presente trabajo se demuestra un 5,2\% de positividad en perros mascota de zonas endémicas contra un $1,6 \%$ en mascotas de zonas no endémicas; por el contrario el porcentaje de positividad de perros callejeros fue independiente de su procedencia. El hallazgo de perros mascotas infectados es de importancia epidemiológica por su cercanía al hombre y además por la posibilidad de que los triatominos se alimenten de estos hospedadores.

Refiriéndose a las preferencias alimentarias de Triatoma dimidiata en Costa Rica, en dos trabajos se coincide en considerar que el vector presenta un comportamiento marcadamente antropofílico ${ }^{4,10}$. Al respecto, sangre humana se encontró en $67 \%$ de los triatominos capturados en el área domiciliar y peridomiciliar ${ }^{10}$; sangre de perro fue encontrada en el $50 \%$ de tales trasmisores ${ }^{10}$. El $40 \%$ de los insectos obtenidos en uno de los estudios fueron positivos por la mezcla de sangre humana y sangre de perro $^{10}$. Si consideramos que el $6,2 \%$ de los perros analizados fueron positivos (Tabla 1), se establece un nexo epidemiológico importante de estos animales en la posible transmisión de esta parasitosis.

En el presente estudio se encontró un 12,2\% de infección en perros callejeros independiente del lugar de captura. Similar a lo que se ha propuesto en Panamá ${ }^{11}$, estos animales podrían haberse infectado al compartir el mismo nicho ecológico con las ratas que son también anima-

Tabla1. Prevalencia de anticuerpos contra Trypanosoma cruzi en perros mascota y callejeros en zonas endémicas y no-endémicas de Costa Rica

\begin{tabular}{|c|c|c|c|c|c|c|}
\hline \multirow[t]{2}{*}{ Tipo de localidad } & \multicolumn{2}{|c|}{ Perros mascota } & \multicolumn{2}{|c|}{ Perros callejeros } & \multicolumn{2}{|c|}{ Total } \\
\hline & Positividad* & $\%$ & Positividad* & $\%$ & Positividad* & $\%$ \\
\hline endémica & $3 / 58$ & 5,2 & $6 / 49$ & 12,2 & $9 / 107$ & 8,4 \\
\hline no-endémica & $1 / 61$ & 1,6 & $1 / 8$ & 12,5 & $2 / 69$ & 2,9 \\
\hline Total & $4 / 119$ & 3,3 & $7 / 57$ & 12,3 & $11 / 176$ & 6,2 \\
\hline
\end{tabular}

* Número de animales positivos/número total de animales estudiados 
Tabla 2. Prevalencia de anticuerpos contra Trypanosoma cruzi en perros de acuerdo al sexo

\begin{tabular}{lrr}
\hline Sexo & Positividad $^{* *}$ & $\%$ \\
\hline Hembras & $4 / 79$ & 5,06 \\
Machos & $7 / 69$ & 10,10 \\
Total* & $11 / 176$ & 6,25 \\
\hline
\end{tabular}

** Número de animales positivos/número total de animales estudiados.

* De veintiocho perros no se tiene información.

les peridomiciliares.

Desde el punto de vista veterinario es importante considerar también que la tripanosomosis causa en perros enfermedad cardíaca, demostrada por disturbios en la conducción y arritmias ventriculares y supraventriculares ${ }^{12-14}$ así como signos propios secundarios a esta condición tales como ascitis, estrés respiratorio, efusión torácica y cianosis ${ }^{15}$.

En conclusión, el hallazgo de un $6,2 \%$ de perros infectados por $T$. cruzi es importante en la epidemiología de esta parasitosis en nuestro país.

\section{RESUMEN}

Se estudió la seropositividad por Trypanosoma cruzi en perros callejeros y mascota en zonas endémicas y no endémicas de Costa Rica. En perros mascota de zonas endémicas se encontró un 5,2\% mientras que en zonas no endémicas fue de 1,6\%. En perros callejeros el porcentaje de positividad fue de $12 \%$ independiente de si fueron capturados en zonas endémicas o no endémicas.

\section{REFERENCIAS}

1.- SCHMUNIS A G. La tripanosomiasis americana como problema de salud pública. La Enfermedad de Chagas y el Sistema Nervioso. Organización Panamericana de la Salud. Publicación Científica $\mathrm{N}^{\circ}$. 547, Washington DC 1994, pp 3-31.

2.- DUSANIC D G. Trypanosoma (Schyzotrypanum cruzi). En: Parasitic Protozoa Second Edition Volumen 1. Ed. (J. P. Kreier and J.R. Baker), Academic Press, Inc. 1991, pp 137-94.

3.- GÜRTLER R E, CECERE M C, PETERSEN R M, et al. Chagas disease in north-west Argentina: association between Trypanosoma cruzi parasitaemia in dogs and cats and infection rates in domestic Triatoma infestans. Trans R Soc Trop Med 1993; 87: $12-5$.

4.- ZELEDON R, SOLANO G, BURSTIN L, SWARTZWELDER J C. Epidemiological pattern of Chagas' disease in an endemic area of Costa Rica. Amer J Trop Med Hyg 1975; 24: 214-25.

5.- LAURICELLA M A, CASTANERA M B, GURTLER R E, SEGURA E L. Immunodiagnosis of Trypanosoma cruzi (Chagas' disease) infection in naturally infected dogs. Mem Inst Oswaldo Cruz 1998; 93: 501-7.

6.- GÜRTLER R E, CECERE M C, RUBEL D N et al. Chagas disease in north-west Argentina: infected dogs as a risk factor for the domestic trasmission of Trypanosoma cruzi Trans R Soc Trop Med Hyg 1991; 85: 741-5.

7.- GÜRTLER R E, COHEN J E, CECERE M C et al. Influence of humans and domestic animals on the household prevalence of Trypanosoma cruzi in Triatoma infestans populations in northwest Argentina. Am J Trop Med Hyg 1998; 6: 748-58.

8.- COHEN J E, GÜRTLER R E. Modeling household trasnmission of American trypanosomiasis. Science 2001; 293: 694-8.

9.- ZELEDON R, SOLANO G, SAENZ G, SWARTZELDER J C. Wild reservoirs of Trypanosoma cruzi with special mention of the Opossum, Didelphis marsupialis, and its role in the epidemiology of Chagas' Disease in an endemic area of Costa Rica. J Parasitol 1970; 56: 38.

10.- CALDERON-ARGUEDAS O, CHINCHILLA M, GARCIA F, VARGAS M. Preferencias alimentarias de Triatoma dimidiata (Hemiptera: Reduviidae) procedentes de la Meseta Central de Costa Rica a finales del siglo XX. Parasitol al Día 2001; 25: 3-4.

11.- BLANDON R, LEANDRO I M, JOHNSON CM. Clinical, electrocardiographic and angiographic evaluation of natural reservoirs of Chagas' disease in the Republic of Panamá. Rev Med Panamá 1995; 20 : 108-15.

12.- BARR S C, SCHMIDT S P, BROWN C C, KLEI T R. Pathologic features of dogs inoculated with North American Trypanosoma cruzi isolates. Am J Vet Res 1991; 52: 2033-9.

13.- MEURS K M, ANTHONY M A, SLATER M, MILLER M W. Chronic Trypanosoma cruzi infection in dogs: 11 cases (1987-1996). J Am Vet Med Assoc 1998; 15: 497-500.

14.- WILLIAMS G D, ADAMS L C, YAEGER R G, McGRATH R K. Naturally occurring tripanosomiasis (Chagas' disease) in dogs. J Am Vet Med Assoc 1977; 171: 171-7.

15.- BARR S C, SIMPSON R M, SCHMIDT S P, BUNGE M M . Chronic dilatative myocarditis caused by Trypanosoma cruzi in two dogs. J Am Vet Med Assoc 1989; 1: 1237-41. 